\title{
Research on Agro-forestry compound ecological industry patterns in Beijing mountainous areas
}

\author{
Chunyan Zhong ${ }^{1, a}$, Jinhua Wang ${ }^{2, b}$, Jinghua Wang ${ }^{3, c}$ \\ ${ }^{1}$ Institute of Comprehensive Agriculture Development Beijing Academy of Agricultural and Forestry \\ Sciences, Beijing 100097; \\ ${ }^{2}$ Beijing Haidian District Landscaping Group, Beijing 100089; \\ ${ }^{3}$ China Rural Technology Development Center, Beijing 100038 \\ azhongchunyan75@126.com, bwangjinhua0625@126.com, 'cwangjinghua@126.com
}

\section{Keywords: Mountainous area; Agro-forestry industry; pattern; countermeasure}

Abstract: Building a multi-level, multi-functional, highly effective forest compound ecological syste $\mathrm{m}$ is the important measure of developing the limited land resources and revitalizing the valley econo my in mountainous areas. It is also a main development direction of mountain forestry. This paper su mmarizes the main modes of Agro-forestry ecosystem industry in Beijing mountainous areas and mak es evaluation analysis on the typical models. And then, it advances the layout ideas and puts forward some development countermeasures on accelerating the development of Agro-forestry industry in Bei jing mountainous areas from the aspects of industrial support policy, technology promotion, industrial transformation and upgrading, brands establishing of characteristic products, etc.

\section{Introduction}

Beijing mountainous areas accounting for $62 \%$ of the total area of the city, is an important part of Beijing tourism industry resources as well as an important support for the capital ecological civilization and sustainable development. Such development models as Valley economy, Forests economy appearing in recent years have added new highlights for the development of Beijing mountainous area. Development of Agro-forestry compound ecological industry is an effective approach to further safeguard the sustainable development of mountain ecological environment, and quickly enrich farmers.

\section{Mainly Agro-forestry ecological industry patterns of Beijing mountainous areas}

Development ecological Agro-forestry industry in Beijing mountainous areas has obvious coordinated industrialization development effects since it can reciprocally combine recent and long term benefits of raising income in recent time and gaining trees in long-term. Ecological Agro-forestry industry not only improves the utilization efficiency of land resources, but also enhances the efficiency of biomass per unit area and light energy. Which can extend the 'producer- consumer-decomposer' chain of industrial economy and achieve the closed type cycle of material-energy flow. At present, the following main kinds of ecological Agro-forestry industry patterns are existing in Beijing mountainous areas.

Forestry-mushroom model

Forestry-mushroom model is a model planting edible mushrooms as shii-take and chestnut mushroom under trees with high canopy density, abandoned branches as part of the components of the edible mushroom spawn culture medium. The model has fully utilized the characteristics of the districts under trees as higher relative humidity, enough oxygen, low light intensity, small temperature difference between day and night. Used mushroom spawn culture medium can also be used as compost material to produce organic fertilizer returned to forestland. Which forms a virtuous cycle. Huairou district chestnut planting area is wide and its production occupies more than $60 \%$ of the total output in Beijing. Bohai town, Jiu Duhe town and other towns are the main chestnut production area. Each year a large number of chestnut branches and chestnut shells are produced. In 2008, the research group had 
tried to use chestnut waste as the main raw material to produce chestnut mushroom spawn culture medium and planted experimentally in chestnut forests in Xing Shutai villiage, Jiu Duhe town. Success was achieved.

Forestry-poultry model

Forestry-bird mode is an effective ecological circular economy mode that breeding chickens, ducks, geese and other types of poultry in forest lands or gardens, fully utilized abundant forests insects, weeds and other resources. Forestry-bird model can save feeding cost, simultaneously the poultry dung can be returned to the soil as fertilizer to greatly increase the soil organic matter and promote the growth of trees. In mountain areas, Forestry-bird mode is one of the common Agro-forestry development modes with high economic benefits.

Forestry-crop model

For the original economic forest of low planting density, according to the situation of woodland proper interplanting can improve land utilization rate, significantly increase the economic benefits of per unit area of land and increase the income of the farmers. In a demonstration chestnut orchard of $\mathrm{Ci}$ muchuan village, Da zhuangke town, Yanqing county, research group have interplanted varieties of economic crops as black peanuts, potatoes, purple sweet potatoes, black beans. Agro-forestry efficient cultivation mode was explored, farmers income was doubled.

Forestry-medicine model

Forestry-medicine mode refers to interplant hygrophilous and shade-enduring Chinese medical herbs in the forests. After interplanting, due to aborative management, the growth speed of original forest also greatly accelerated. Because of special habits, part of the medical materials even have played an important role in prevention of forest diseases. This model has achieved a win-win situation between ecology and incomes.In Beijing mountainous forests, such Chinese herbal medicines are generally chosen as the scutellaria baicalensis, radix scrophulariae, rhizoma anemarrhenae, chrysanthemum, semen cassiae, American ginseng, honeysuckle. In Yanqing county Dazhuangke township Cimuchuan village, Group adopts the model of Chinese chestnut forests set of radix scutellariae in agroforestry, obtain In a demonstration chestnut orchard of Cimuchuan village, Dazhuangke town, Yanqing county, research group have interplanted scutellaria baicalensis and obtained good effect of more than RMB 2000 yuan income per mu.

Forest-herb model

In the Forest-herb model, herbaceous plants have exerted several main functions. They can effectively restrain soil erosion and sand dust of sapling forests; It can improve the tree growth environment, reduce the surface temperature in summers, reduce plant diseases and insect pests occurrence and improve the survival rates of trees. The ground parts after mowing can be directly used as trees green manure and the underground roots can improve soil physical and chemical properties with higher water and fertilizer retention ability. In Beijing mountainous forests, such herbaceous plants can be chosen as bur clover, perennial ryegrass, red clover, white clover, orchard grass, awnless brome, pennisetum.

\section{Evaluation analysis on the typical Agro-forestry ecological industry patterns of Beijing mountainous area}

The research methods

This study Evaluates the models of Forestry-mushroom model, Forestry-poultry model, Forestry-medicine mode , Forestry-crop model, Forest-herb model just according to the topic experiment results. And input, output, output value, net income, input-output ratio of each model has been analyzed. Specific results are shown in Table 1. 
Table 1 The typical pattern economic benefit evaluation analysis table

\begin{tabular}{|c|c|c|c|c|c|}
\hline models & tree species & $\begin{array}{c}\text { income per } \\
\text { mu } \\
\text { [Yuan] }\end{array}$ & $\begin{array}{l}\text { output } \\
\text { per mu } \\
{[\mathrm{kg}]}\end{array}$ & $\begin{array}{c}\text { net } \\
\text { income } \\
\text { [Yuan] }\end{array}$ & $\begin{array}{l}\text { input-out } \\
\text { put ratio }\end{array}$ \\
\hline $\begin{array}{l}\text { Forestry-mushroom model } \\
\text { (Chinese chestnut-chestnut } \\
\text { mushroom) }\end{array}$ & chestnut & 11900 & 1050 & 9100 & 1.74 \\
\hline $\begin{array}{l}\text { Forestry-poultry model } \\
\text { (Chinese chestnut-chicken) }\end{array}$ & chestnut & $\begin{array}{c}1200[80 \mathrm{chic} \\
\mathrm{kens} / \mathrm{mu}]\end{array}$ & 160 & 3600 & 4.0 \\
\hline $\begin{array}{l}\text { Forest-herb model } \\
\text { (Chinese chestnut-tea } \\
\text { chrysanthemum) }\end{array}$ & chestnut & 300 & 200 & 2700 & 10.0 \\
\hline $\begin{array}{l}\text { Forestry-crop model } \\
\text { (Chinese chestnut-black } \\
\text { peanuts) }\end{array}$ & chestnut & 500 & 300 & 2000 & 5.0 \\
\hline $\begin{array}{l}\text { Forestry-crop model } \\
\text { (Chinese chestnut-purple } \\
\text { sweet potatoes) }\end{array}$ & chestnut & 1200 & 1500 & 2000 & 2.67 \\
\hline $\begin{array}{l}\text { Forestry-crop model } \\
\text { (Chinese chestnut-potatoes) }\end{array}$ & chestnut & 400 & 1000 & 1600 & 5.0 \\
\hline $\begin{array}{l}\text { Forestry-crop model } \\
\text { (Chinese chestnut-black } \\
\text { beans) }\end{array}$ & chestnut & 300 & 800 & 2100 & 8.0 \\
\hline $\begin{array}{l}\text { Forestry-medicine model } \\
\text { (Chinese chestnut - } \\
\text { scutellaria baicalensis) }\end{array}$ & chestnut & 150 & 100 & 2350 & 16.67 \\
\hline $\begin{array}{l}\text { Forest-herb (flower) model } \\
\text { (peach forest-day lilies) }\end{array}$ & peach tree & 350 & - & 1000 & 3.89 \\
\hline $\begin{array}{l}\text { Forest-herb (flower) model } \\
\text { (peach forest- clovers) }\end{array}$ & peach tree & 80 & - & 800 & 11 \\
\hline $\begin{array}{l}\text { Forest-herb (flower) model } \\
\text { (persimmon trees-clovers) }\end{array}$ & $\begin{array}{l}\text { persimmon } \\
\text { tree }\end{array}$ & 80 & - & 800 & 11 \\
\hline
\end{tabular}

Results analysis

By the above calculation of various models, such following conclusions can be drawn.

(1) Inputs and incomes are not much difference between the four Forestry-crop models. Because of its relatively lower technical requirements while nice incomes, Forestry-crop model is suitable for the Beijing mountainous areas having plentiful laborers with common personnel quality.

(2)The net incomes of Forestry-mushroom model (chestnut-chestnut mushroom) are the best, Forestry-poultry model (Chinese chestnut-chicken) is second; Forest-herb models of peach and persimmon are the lowest. However, the inputs of Forestry-mushroom model (chestnuts and chestnut mushroom) and Forestry-poultry model (Chinese chestnut -chicken) are large, since they require more labor, relative higher technologies, and more risks during the cultivation of chestnut mushrooms and chickens. And the input-output ratios of the two models are low. Forestry-mushroom model (chestnut-chestnut mushroom) are the best, Forestry-poultry model (Chinese chestnut-chicken) are suitable for the mountainous areas having plentiful laborers with higher personnel quality.

(3)Though the output of three Forest-herb (flower) models of peach forest-day lilies, peach forest-clover and persimmon tree-clover are low, and the incomes(In the research, labor cost saving and fertilizer cost saving are calculated as incomes) are lower as well. Nevertheless, it can be regarded as a nice model yet based on its high operability and good ecological benefit since it can save labor cost 
on weed control and save cost on fertilizer by making clover be a part of fertilizer. This model is suitable for the areas relative lack of labor.

(4)Forestry-medicine model(Chinese chestnut-scutellaria baicalensis) is a very good model with not much labor, easier management and higher income. Forest-herb model(Chinese chestnut-tea chrysanthemum) is worthy to popularized as well. The input-output ratios of the two models are relatively higher.

\section{Analysis on space layout of Agro-forestry industry in Beijing mountainous areas}

\section{General ideas}

Beijing mountainous areas Agro-forestry ecological industry should implement the interactive development mechanism of one core zone coexisted five districts and two radiative zones. Thus new typical development models can be gradually established, which have regional characteristics, outstanding Agro-forestry ecological industrial strength, beautiful ecological environment, meanwhile the farmers are living in affluence.

(1)Through strengthening agriculture with science and technology pointed at fine breeds and good methods, Intensifying Agro-forestry ecosystem technology integration and innovation in core zones, adopting the development path of introduction, research, technology integration, demonstration, popularization, seizing tightly the three key points of technological innovation, transformation application, personnel training, the modern industry of Agro-forestry ecosystem with technology integration, production procedures standardization and production management informationization should be achieved .

(2)Agro-forestry ecosystem industry development should be stimulated by the integration linkage of urban and rural areas. The urban management concepts and advantages on technology, capital, market, information should be fully absorbed

The industrial distribution

According to the actual development situation of Agro-forestry ecosystem industry in Beijing mountain area, the industrial distribution of one core, two radiative zone is constructed based on ecology and production similarity. The layout is as follows.

(1)Core zone

The core zone includes districts of Yanqing, Huairou, Miyun, Pinggu and Men tougou. As Beijing urban water conservation areas, such districts have good ecological environment and rich forests resources and relatively large development space of Agro-forestry ecosystem industry. According to the suburb resources survey research, one of ' 221 action plan' researches of Beijing urban modern agriculture, carried by Institute of Comprehensive Agriculture Development Beijing Academy of Agricultural and Forestry Sciences, there are four main economic forest species suitable for the development of Agro-forestry ecosystem industry in Beijing mountainous area as apple, chestnut, walnut and peach. 1) Apple industry of mountain warm zones is distributed in the former hills of the south and north mountains of Yanqing basin, the platforms of the east hills in Miyun district. 2) Chestnut industry focused on the Da zhuangke town of Yanqing district, four towns of norther west valleys of Huairou, fours towns of Shi cheng, Feng jiayu, Bu laotun and Gaoling of Miyun district and Luo ying town of Pinggu district, etc. 3) walnut industry of shallow mountain valleys is mainly distributed in such counties as Pinggu, Huairou and Miyun. 4) Peach industry of hills centers Pinggu district, including suitable areas of other districts. Although various types of Agro-forestry ecosystem industry patterns can be carried out in core zone, ecological environment protection should be paid close attention to. As to Forest-poultry mode, poultry breeds and breeding density should be concentrated on .

(2) Nearby radiative zone

Nearby radiative zone adjacent to the core zone, includes Shunyi and Changping district. There are three main fruit trees in nearly radiative zone as apple, chestnut and pear. 1) Apple industry of mountain warm zones concentrates on Shunyi and Changping district. 2) Chestnut industry concentrates on the Xia zhuang town and Hei shanzhai town of Changping district. 3) Pear industry is layout in Shunyi 
district, forming the chaobai river sand pear industry. In early radiative zone, such models of Forest-herb, Forest-medicine and Forest-mushroom can be carried out.

(3) West radiative zone

West radiative zone mainly refers to Fangshan district. The main economic forest species in this zone are persimmon, walnut, and pear. Persimmons are mainly planted in Fangshan, forming a persimmon industry area of hilly loess region . Various Agro-forestry ecosystem industry patterns can be carried out in the zone. Due to its deep development foundation in Fangshan, Forest-mushroom model can be developed vigorously.

\section{Development countermeasures on Beijing mountainous Agro-forestry industry}

Intensifying the planning and support policy of the ecological industry

Firstly, planning should be drawn up before the construction and development of Agro-forestry industry. At present the development of Beijing Agro-forestry ecosystem industry is still lack of planning and design. Agro-forestry industry planning includes analysis on production potential, ecological process, ecological structure, system sensitivity and decision making. The Planning goals are sustainable development, efficient utilization of resources, and the harmony and stability of the industrial relations. Secondly, the preferential policies in view of the Agro-forestry ecosystem industry development in Beijing mountainous areas should be researched according to the development present situation. Such policies includes of encouraging and supporting the development of Agro-forestry ecosystem industry through subsidies, loan guarantee discount, technical support, establishing ecological industry guide funds, land concessions and other ways, increasing the intensity of financial subsidies to the measured soil fertilizer, establishing and improving the system for pollution-free agricultural products and green product identification, encouraging the public to purchase ecological agriculture production, overall arranging of Agro-forestry ecosystem industry development funds with the fund size of each area county is about RMB 200 million yuan supported not less than three years, specializing utilization of subsidies for Agro-forestry ecosystem industry, supporting the establishment of compound ecological industrial parks and production bases. Finally, the relevant departments as Agricultural commission, Landscape and Forestry Bureau, Water Supplies Bureau, Agricultural Bureau, Tourist Administration should coordinate more tightly to provide supports on infrastructure construction, capital guarantee and industry policy etc. And further promote the sustainable development of forest compound ecological industry.

Strengthening the ecological technology popularization and skills training

Firstly, relying on rural coordinator team of science and technology, strengthening the farmers with the popularization of ecological agricultural knowledge, publicity and promotion of appropriate Agro-forestry ecosystem industry models, helping farmers to master Agro-forestry production technology and actively guiding farmers to participate in the construction and development of ecological Agro-forestry industry. Secondly, researching, developing and popularizing new technologies related to Agro-forestry ecosystem industry such as environmental protection and resource development technology (soil and water conservation management technology, sand prevention technology, etc.), fertilizer application technology, breeding technology, integrated pest control technologies centering the reform of farming system, natural enemy propagation technique and the biological pesticides development and application technique, etc. Thirdly, formulating green, organic Agro-forestry ecosystem industry standards and technical norms emphasis on the production process standardization with technological support. The government should Play a guiding role of supporting the professional cooperative organizations and trade associations to strengthen technical promotion and training, improve local managers, the farmers production skills and make them meet the demands of the Agro-forestry ecosystem industry development.

Stimulating Agro-forestry industrial upgrading transformation, dominated by ecological tourism

Urban modern agriculture in Beijing is a highly integration industry of the first, second and tertiary industry. So is Agro-forestry, since it is a form of urban agriculture. Therefore, the Agro-forestry 
ecosystem industry in Beijing mountainous area should highlight the eco-service industry status of ecological tourism. As a service industry, eco-service industry mainly provides ecological products and services, including ecological product sales, hotel catering, ecological tourism, etc. Developing eco-tourism in Beijing mountainous areas should pay more attention to such following aspects. First, combining eco-tourism with the Agro-forestry industry through exploring the intrinsic function relations of the two industries and connecting tightly the agricultural culture, ecological civilization with tangible products. On one hand, attracting tourists by the natural or artificial favorable ecological conditions and creating close communications between urban and rural residents by interactive activities. On the other hand, offering visitors the local agricultural products. Second, developing tourism under the limit of the environmental bearing capacity through controlling the activity intensity and tourists amount. Third, strengthening the environmental protection education by the means of installing some publicity facilities in the scenic spots to enhance tourists' environmental protection consciousness and strengthening management simultaneously. Fourth, establishing a combined ecological experience industry through promoting the development of relative eco-service industry about fruit picking, leisure and entertainment, ecological product sales brought along with ecological tourism.

Strengthening the ecological agriculture and economic forestry, creating characteristic high-quality goods and improving the benefits of Agro-forestry products.

Based on its good environment and rich agricultural resources, Beijing mountainous areas have the advantages of developing ecological Agro-forestry. And the development prospect is strengthening the ecological Agro-forestry industry to form scales and characteristics. Concrete countermeasures are as follows. First, combined with local Agro-forestry production base, cultivating brand of ecological agriculture with local characteristics. Continually developing characteristic forestry and fruit industry of apple, chestnut, peach, persimmon, pear, grape, walnut etc. and such efficient planting industry of competitive products as minor crops, wild vegetables and herbs. Second, continually advancing the standardization of agricultural productions, popularizing advanced Agro-forestry production technology and increasing the proportion of green, organic agricultural products by utilizing the mountainous environment advantages of less pollution. Third, strengthening the support of Agro-forestry production base construction, which is helpful for the scale and intensification of ecological agricultural production. Fourth, the industry associations should fully play a role of coordination and guidance on the ecological agricultural production to unify productions and sales and to improve the overall competitiveness of ecological agriculture and forestry products.

\section{Acknowledgements}

This work was financially supported by Beijing Municipal Bureau of Finance.

\section{References}

[1] Huang Baolong, Huang Wending: Chinese Journal of Ecology,10(3),1991,pp27-32, In Chinese

[2] Wu Jingjing: Science Guidance,2003(2):89,189, In Chinese

[3] Zhang Yifeng,etc. : Journal of Geographical Sciences,2009,64(10):1231-1242, In Chinese

[4] Li Xiangqin, Wu Dianting, Song Jinping: Journal of Beijing Normal University , 2005,41(4):437-440, In Chinese

[5] Meng Ping, Zhang Jinsong: Research on the Agro-forestry Ecosystem. Beijing, Science Press, 2004, In Chinese 